\title{
Does Your Mind Push? Mental Simulation of Context-Independent Monosyllabic Verbs in Chinese
}

\author{
Yingxia $\mathrm{Li}^{1} \&$ Lin $\mathrm{Wu}^{2}$ \\ ${ }^{1}$ School of Software, Dalian University of Technology, Dalian, China \\ ${ }^{2}$ Overseas Education College, Xiamen University, Xiamen, China \\ Correspondence: Yingxia Li, School of Software, Dalian University of Technology, Dalian, China. E-mail: \\ amylyx@sina.com
}

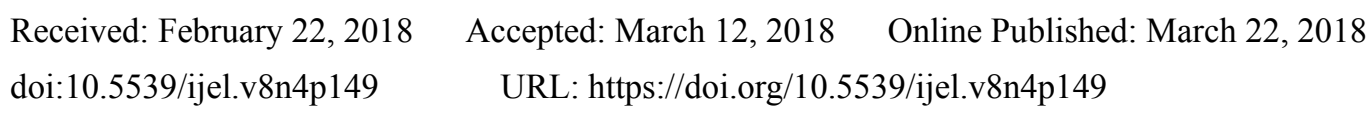

\begin{abstract}
This paper investigates the semantic simulation of the monosyllabic verbs in Chinese. It tries to find out whether the sensorimotor circuitry is involved in the processing of the verb meanings, in particular, the monosyllabic verbs independent of the context. E-prime 2.0 is used in the experiment to record the RT (reaction time) of the subjects when they process the verbs with a colored bar as the background of each verb. The orientations of the bars either match with the direction indicated in the verb meanings or not. The results show that even without specific context, the processing of the verb meanings still require automatic activation of the sensorimotor system.
\end{abstract}

Keywords: Chinese verbs, sensorimotor, semantic simulation, mental simulation

\section{The Theoretical Basis of the Simulation Semantics of Language Research}

According to the theory of Embodied Cognition, the semantic understanding of language is based on people's experience and interaction with the world (Fillmore, 1982; Lakoff, 1987; Fauconnier, 1997), not just a logical system (Barwise \& Perry, 1983). Advanced cognitive activities include simulations and re-enactments of low-level perception, movement, and emotional experience. Semantic processing depends on the perceptual motor system and reflects the characteristics of this system. The simulation semantics is derived from the embodiment theory. This theory holds that language users process and understand language through psychological simulation.

\subsection{The Perceptual Representation of Lexical Processing}

Native language processing is closely related to spatial cognition and sensory movement (Dudschig et al., 2014). Using native languages to describe events automatically activates motor responses (e.g., Glenberg \& Kaschak, 2002; Loftus \& Palmer, 1974). For example, subjects used different verbs (contacted, bumped into, collide with, smashed into) to describe the speed of the vehicles in the experiment. It was found that the visual impact produced in the subjects' mind greatly altered the time length of verb processing. Interestingly, the more intense the impact was, the shorter time the subjects used. In other words, visual representations influence the speed of language understanding (Zwaan, 2004).

Besides visual representations of verb processing in the brain, experimental results also confirm that the brain has a specific area corresponding to the movement of different parts of body, and these areas are of bottom-to-top distribution in the in the somatosensory cortex of the cerebral cortex (Pulvermüller et al., 2001; Hauk \& Pulvermüller, 2004; Pulvermüller et al., 2005, DE Lafuente \& Romo, 2004). Using the interference effect, Bergen (2010) studied the semantic processing of verbs in certain parts of the body, and found that the interference effect was produced when two verbs in the same body parts were processed. For example, "kick" and "waltz" in the English language are the movements triggered by the foot, and hence an interference effect was evoked; while the verb "scratch", an action from the hand, was not affected. When examined, these action verbs automatically activated the corresponding motor cortex in the brain. For further evidence, Bergen (2010) conducted a psychological simulation study of body action words in the Cantonese language. The experimental results are consistent with those in the English language, as the stimulus materials are the same. In addition, neuroimaging studies have found that people activate motor regions associated with actions in their brain when 
they look at tools or see tool words. These results directly or indirectly demonstrate that language understanding relies on the experience of activating sensorimotor system (Dudschig et al., 2014; Barsalou, 1999; Glenberg \& Gallese, 2012; Glenberg \& Kaschak, 2002; Zwaan \& Madden, 2005). In a word, language processing depends on perceptual representation.

\subsection{Spatial Representation of Lexical Processing}

Apart from perceptual representations, language processing also produces spatial representations. For example, Tamly (1983), Lakeoff (1987), and Langacker (1987) believe that language and concept process have metaphorical associations with the "image schema". Boroditsky (2000) found that native speakers of Chinese tend to use vertical image schema to understand the concept of time, whereas native speakers of English are more likely to use horizontal image schema. Zwaan et al. (2001, 2002, 2005) conducted a series of experiments and found that the description of a upright water cup and a upside-down one on the table evoked different spatial representations; the description of the nails in the wall and the nails in the floor also produced different spatial representations. By using sentence-graphic collocations, these experiments indicated that language processing produced the spatial representation of the real object.

However, it is hard to say whether the spatial representations is caused by the context of the sentence or the words themselves. How about words without a specific context? Zwaan et al. (2003) found that when a pair of nouns (e.g. the crown and the root of the tree) presented in a manner consistent with the way they were presented, the reaction time was shorter; in other words, if the former (the crown) appears above and the latter (the root of the tree) appears below, the response time is faster than vise the versa. In another experiment, a noun that appears in the middle of the screen, such as "the sun" and "shoes", affects the judgment of the upper and lower directions (Estes, Verges, \& Barsalou, 2008).

Other studies have found that verbs (Verges \& Duffy, 2009) and sentences (Bergen et al., 2007) also produce similar results (Dudschig \& Kaup, 2014). One typical experiment was conducted by Richardson (2001). In the experiment, the experimenters asked participants to indicate the direction of the given verbs by drawing arrows. The results showed that both concrete and abstract verbs are consistent with the spatial representations of those arrows. However, this task is not instantaneous, so the spatial representations are likely to be the result of the human interventions. Therefore, Richardson et al. (2003) improved the experimental method and further investigated whether the spatial orientation effect was automatically activated in the process of understanding the verbs in real time. The results showed that the sentence comprehension tasks also affected the identification of the graphics. However, since the experiment uses sentences as stimuli, it is quite possible that the spatial orientation effect is triggered by the situation constructed by the sentence rather than the verbs.

In order to find out whether the space element is automatically activated in Chinese verbs, Limei Wu (2006) adapted the experimental material compiled by Richardson. The assumption is that if negative sentences also activate spatial orientation effect, the situational construction of the sentences plays no role in the spatial representation. The conclusion, as a result, proves that negative sentences in Chinese do create spatial orientations. Therefore, $\mathrm{Wu}(2006)$ believe that it is the verbs that activate the spatial representation rather than the situation constructed by the sentence.

However, Bergen et al. (2008) had different findings. In their experiment, the stimulus materials used three different kinds of sentences made up of the same intransitive English verbs, which indicating concrete, metaphorical and abstract concept respectively. They found that although the processing of specific sentences significantly influenced the task of the image identification, the metaphorical and abstract sentences activated very little spatial orientation representation. Therefore, they concluded that the spatial orientation representation was caused by the situation constructed by the sentence.

To sum up, there are still unresolved problems in the spatial representation of verb processing. It is still not clear whether the spatial representation of verbs in different languages are context independent. One explanation of the divergence might be the different roles of verbs in English and Chinese. Liu (2010) believes that Chinese is a verb type language and English is a noun language. The role of verbs in Chinese is more important than that in English. There are many gerunds in English, and most verbs can be converted into gerunds, serving as a noun in a sentence. In contrast, no such grammatical phenomenon is found in Chinese.

Therefore, in this paper we use monosyllabic verbs, which has rarely been studied, as the stimuli to investigate whether there is a spatial orientation representation of processing in Chinese in the absence of context, and whether the spatial representation is automatically activated during processing. In order to solve these problems, we designed two experiments to investigate whether the Chinese monosyllabic verbs can automatically activate the horizontal or vertical directions. 


\section{Method}

\subsection{Subjects}

30 undergraduates, 28 males and 2 females, all majoring in software engineering participated in the study. All the subjects, aged from 18-21, have normal or corrected-to-normal vision. They are all native speakers of Chinese, no dyslexia or reading disorder. They received a small amount of compensation after the experiment.

\subsection{Materials}

In the experiment, 80 Chinese monosyllabic verbs were used as stimulus words together with 40 fillers. The 80 experiment verbs denote vertical or horizontal motions, for example, 提 (lift) and 推 (push); the 20 filler verbs with no orientation inclination, for example, 笑 (laugh). All the verbs are presented in the center of a colored bar, and the bar is also presented in the center of the screen of a computer.

\subsection{Procedure}

E-prime 2.0 software was used in the experiment. Each trial consisted of a fixed point in red, a visual stimulus of a Chinese monosyllabic verb with a colored bar as the background, either in vertical or horizontal direction. We used the Stroop paradigm to interfere with tasks. Each of the task had a single syllable verb. The subjects were asked to judge the color of the bar. In the experiment, 60 single-syllable verbs were put in the middle of the colored bar. The subjects first saw a red gaze point, a red or blue colored bar, and a single syllable Chinese verb in the middle. The bar, either in horizontal or vertical direction, appeared in the center of the screen. The participants had $800 \mathrm{~ms}$ to judge the color of the bar. If the bar was blue, pressed the F key; if red, pressed the J key. The order of the stimulus was completely random.

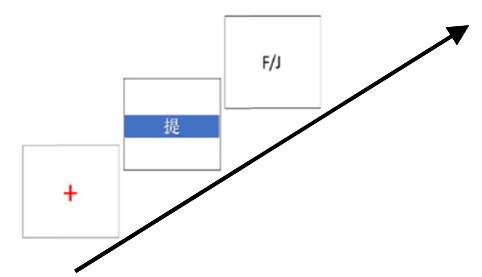

Figure 1. The horizontal bar as the background of the trial

(The Chinese character “提” means "lift”, indicating a vertical movement in contrast with the orientation of the bar.)

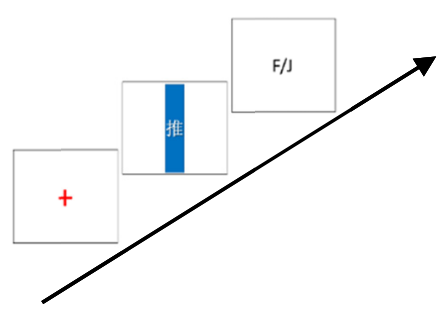

Figure 2. The vertical bar as the background of the trial

(The Chinese character “推” means "push”, indicating a horizontal movement in contrast with the orientation of the bar.)

All the data were collected immediately after the subjects finish the trials. The two behavioral indexes are the reaction time (RT) and the accuracy of the answer. To ensure the validity of the result, the record will be discarded if the accuracy is lower than $75 \%$, which suggests that the subjects did not understand the experiment or did not cooperate. All the data were processed by the SPSS 16.0.

\section{Results and Discussion}

All the data are valid, since the accuracy of the answer is all above $75 \%$. The RT of the matched words-bar orientation is significantly faster than the filler words $[\mathrm{p}=0.016<0.05]$. 
Table 1. The comparison of the matched and non-match orientations of the words and the bar

\begin{tabular}{lllll}
\hline Type & Mean & Std. Diviation & $\mathrm{t}$ & Sig. \\
\hline Match & 192.476 & 513.426 & 1.921 & 0.064 \\
Non-match & 247.657 & 564.132 & 2.357 & 0.025 \\
\hline
\end{tabular}

As is shown in the table above, subjects took significantly longer to judge the color of the bar when the meaning of the verb indicating an opposite orientation (a horizontal bar and a verb with up-down mental simulation). Undoubtedly, the Chinese characters on the bar must have produced an interference effect. It also indicates that additional mental resources are involved in the cognitive process when recognizing the bar color in the non-matched conditions.

The results of the experiment build on the embodied theories that language understanding involves the participation of the sensorimotor system, and the process is spontaneous and automatic. For one thing, the process is automatically evoked because the subjects have never been told to read the words (the Chinese characters) on the screen. All they need is to tell the color of the bars. However, as the words (characters) emerge right in the middle of the screen, a position that cannot be overlooked when the subjects focus on the bars, the interference is totally unaware. This perceptual information automatically triggers the orientation information processed in the mind. In other words, the sensorimotor experience is activated when the subjects see the Chinese characters. The additional time is consumed to exclude the interference of the different orientations the Chinese character triggered and the orientation of the bar itself. It is also interesting to note that even though then non-matched condition cause interference when judging the color, the matched condition does not facilitate the process of the information, comparing with the fillers [ $\mathrm{p}=0.153>0.05]$.

Another purpose of the experiment is to find out whether the mental simulation is constructed by the context of the verbs. As we know, all the transitional verbs are followed by an object, either a concrete thing or an abstract concept. Most of the verbs we use as the stimuli are transitional words, for example, “提” (lift). If it is a monosyllabic verb, it reduces the ambiguity of disyllabic words that are formed by “提”. For example, “提起” means "to mention"; “提出” means "to put forward”; “提问” means "to ask a question". Apart from these, the connotation of disyllabic words greatly rely on their context, or the words follow after. As we can see in “提起往 事”, which means “to talk about the past experience” while “提起水桶” means “to lift a barrel”. Both of the expressions are formed by the verb phrase “提起”, but totally different meanings due to their different objects. Obviously, the context constructed in a sentence plays an essential role in understanding these verb phrases. However, if we tell the participants in advance that all the monosyllabic verbs are actions verbs, that is, all of them indicate a particular action, it reduces the possibility of misunderstanding to the minimum.

Of course, monosyllabic verbs are only one category of Chinese verbs. More work needs to be done for other types of verbs. Nevertheless, this study offers a support for the simulation semantics in the way that understanding an individual verb without any influence of its context still requires the involvement of sensorimotor system. More importantly, this process is automatic. In other words, the result supports the notion that language understanding is embodied. Our future work will focus on how the objects following the verbs or verb phrases influence people language processing, and whether an abstract concept activates sensorimotor circuitry.

\section{Acknowledgement}

This paper is supported by the Basic Research Operating Expenses (DUT16RW110).

\section{References}

Barasalou L. W. (1999). Language comprehension: Archival memory or preparation for situated action? Discourse Processes, 28, 61-80. https://doi.org/10.1080/01638539909545069

Barasalou L. W. (1999). Perceptual symbol system. Behavioral and Brain Science, 22, 577-660. https://doi.org/10.1017/S0140525X99002149

Barwise, K. J., \& Perry, J. (1983). Situations and Attitudes. Cambridge: MIT Press.

Bergen, B., Matlock, T., \& Narayanan S. (2008). Spatial and linguistic aspects of visual imagery in sentence comprehension. Cognitive Science, 31(5), 733-764. https://doi.org/10.1080/03640210701530748

Bergen B. (2005). Mental simulation in spatial language processing. In M. D. Karl (Ed.), Proceedings of the twenty-seventh annual conference of the cognitive science society. Stresa: Karl M D.

Bergen, B., Chang, N., \& Narayan, S. (2004). Simulated action in an embodied construction grammar. 
Proceedings of the twenty-sixth annual conference of the cognitive science society (pp. 108-113). Chicago: Mahwah, NJ.

Bergen, B., Lau, T. T. C., Narayan, S., Stojanovic, D., \& Wheeler, K. (2010). Body part representations in verbal semantics. Memory \& Cognition, 38(7), 969-981. https://doi.org/10.3758/MC.38.7.969

Bergen, B., \& Wheeler, K. (2010). Grammatical aspect and mental simulation. Brain \& Language, 112, 150-158. https://doi.org/10.1016/j.bandl.2009.07.002

Bergen, B., Lindsay, S., Matlock T., \& Narayanan S. (2007). Spatial and linguistic aspects of visual imagery in sentence comprehension. Cognitive Science, 31, 733-764. https://doi.org/10.1080/03640210701530748

Boroditsky, L. (2000). Metaphoric structuring: understanding time through spatial metaphors. Cognition, 75(1), 1-28. https://doi.org/10.1016/S0010-0277(99)00073-6

Boroditsky L. (2001). Does language shape thought?: Mandarin and English speakers' conceptions of time. Cognitive Psychology, 43(1), 1-22. https://doi.org/10.1006/cogp.2001.0748

DE Lafuente, V., \& Romo, R. (2002). A hidden sensory function for motor cortex. Neuron, 36(5), 785-786. https://doi.org/10.1016/S0896-6273(02)01095-4

Dudschig, C., Vega, de la., Kaup, I., \& Kaup, B. (2014). Embodiment and second-language: Automatic activation of motor responses during processing spatially associated L2 words and emotion L2 words in a vertical Stroop paradigm. Brain and Language, 132(5), 14-21. https://doi.org/10.1016/j.bandl.2014.02.002

Fillmore, C. J. (1982). Frame semantics. In The Linguistic Society of Korea (Ed.), Linguistics in the Morning Calm, Hanshin Publishing Company (pp. 111-122). Seoul.

Fauconnier, G. (1997). Mappings in Thought and Language. Cambridge, U.K.: Cambridge University Press. https://doi.org/10.1017/CBO9781139174220

Glenberg, A. M., \& Kaschak, M. P. (2002). Grounding language in action. Psycho-nomic Bulletin \& Review, 9 , 558-565. https://doi.org/10.3758/BF03196313

Glenberg, A., \& Gallese, V. (2012). Action-based language: A theory of language acquisition production and comprehension. Cortex, 48, 905-922. https://doi.org/10.1016/j.cortex.2011.04.010

Hauk, O., Johnsrude I., \& Pulvermüller F. (2004). Somatotopic representation of action words in human motor and premotor cortex. Neuron, 41. https://doi.org/10.1016/S0896-6273(03)00838-9

Klatzky, R. L., Pellegrino, J. W., McCloskey, B. P., \& Doherty, S. (1989). Can you squeeze a tomato? The role of motor representations in semantic sensibility judgments. Journal of Memory and Language, 28, 56-77. https://doi.org/10.1016/0749-596X(89)90028-4

Lakoff, G. (1987). Women, Fire and Dangerous things. The University of Chicago Press: Chicago. https://doi.org/10.7208/chicago/9780226471013.001.0001

Langacker, R. W. (1987). An introduction to cognitive grammar. Cognitive Science, 10(1), 1-40. https://doi.org/10.1207/s15516709 $\operatorname{cog} 1001 \_1$

Lewis, J. W. (2006). Cortical networks related to human use of tools. Neuroscientist, 12(3), 211-231. https://doi.org/10.1177/1073858406288327

Loftus, E. F., \& Palmer, J. C. (1974). Reconstruction of automobile destruction: An example of the interaction between language and memory. Journal of verbal learning and verbal behavior, 13(5), 585-589. https://doi.org/10.1016/S0022-5371(74)80011-3

Li, D. (2010). Chinese Is A Verb Language - On Typological Differences between Verb Languages and Noun Languages. Chinese Teaching in the World, 1(1), 3-7.

Morrow, D. G., \& Clark, H H. (1988). Interpreting words in spatial descriptions. Language and Cognitive Processes, 3(4), 275-291. https://doi.org/10.1080/01690968808402091

Pulvermüller, F., Härle, M., \& Hummel, F. (2001).Walking or talking?: Behavioral and neurophysiological correlates of action verb processing. Brain and Language, 78, 143-168. https://doi.org/10.1006/brln.2000.2390

Pulvermüller, F., Hauk, O., Nikulin, V. V., \& Ilmoniemi, R. J. (2005). Functional links between motor and language systems. European Journal of Neuroscience, 21(3), 793-797. https://doi.org/10.1111/j.1460-9568.2005.03900.x 
Richardson, D. C., Spivey, M. J., \& Eldman, S. et al. (2001). "Language is spatial": Experimental evidence for images schemas of concrete and abstract verbs. Proceedings of the 23rd annual meeting of the cognitive science society (pp. 873-878). Mawhah NJ: Erlbaum.

Richardson, D. C., Spivey, M. J., \& Barsalou, L. W. et al. (2003). Spatial representations activated during real-time comprehension of verbs. Cognitive Sciences, 27(5), 767-780. https://doi.org/10.1207/s15516709 $\operatorname{cog} 2705 \_4$

Talmy, L. (1983). How language structures space. In Pick \& Acredolo (Eds.), Spatial orintation: theory, research and application. Plenum Press: New York. https://doi.org/10.1007/978-1-4615-9325-6_11

Verges, M., \& Duffy, S. (2009). Spatial representations elicit dual-coding effects in mental imagery. Cognitive Science, 33, 969-1181. https://doi.org/10.1111/j.1551-6709.2009.01038.x

Wu, L., Mo, L., \& Wang, R. (2006). The Activation of Spatial Representations in Verb Comprehension. Acta Psychological Science, 38(5), 663-671.

Yang, J., \& Shu, H. (2011). Embodied representation of tool-use action verbs and hand action verbs: evidence from a tone judgment task. Neuroscience Letters, 493(3), 112-115. https://doi.org/10.1016/j.neulet.2011.02.020

Yang, J., Shu, H., Bi, Y., Liu, Y., \& Wang, X. (2011). Dissociation and association of the embodied representation of tool-use verbs and hand verbs: An fMRI study. Brain and Language, 119(3), 167-174. https://doi.org/10.1016/j.bandl.2011.06.001

Zwaan, R. A., Madden, C. J., \& Yaxley, R. H. et al. (2004). Moving words: dynamic representations in language comprehension. Cognitive Science, 28(4), 611-619.

Zwaan, R. A., Stanfield, R. A., \& Yaxley, R. H. (2002). Language comprehenders mentally represent the shapes of objects. Psychological Science, 13(2), 168-171. https://doi.org/10.1111/1467-9280.00430

\section{Appendix}

Table 1. The verbs of vertical motions

\begin{tabular}{|l|l|l|l|l|l|l|l|l|l|}
\hline 拔 & 踩 & 沉 & 傩 & 捣 & 跌 & 蹲 & 挂 & 降 & 揭 \\
\hline 撅 & 捞 & 埋 & 创 & 䢃 & 拾 & 踏 & 捅 & 卸 & 坐 \\
\hline 倒 & 掉 & 顶 & 扶 & 捡 & 浇 & 举 & 砍 & 淋 & 落 \\
\hline 冒 & 捧 & 切 & 摔 & 抬 & 提 & 掀 & 栽 & 蘸 & 砸 \\
\hline
\end{tabular}

Table 2. The verbs of horizontal motions

\begin{tabular}{|l|l|l|l|l|l|l|l|l|l|}
\hline 扮 & 搬 & 拨 & 剥 & 蹭 & 扯 & 撤 & 抻 & 冲 & 传 \\
\hline 摆 & 端 & 涂 & 划 & 晃 & 摚 & 拉 & 栏 & 摸 & 掕 \\
\hline 跑 & 漂 & 扑 & 铺 & 牵 & 撒 & 扫 & 笁 & 射 & 刷 \\
\hline 撕 & 摊 & 踢 & 搓 & 推 & 拖 & 游 & 拽 & 追 & 走 \\
\hline
\end{tabular}

Table 3. Fillers

\begin{tabular}{|l|l|l|l|l|l|l|l|l|l|}
\hline 笑 & 煮 & 数 & 赎 & 吃 & 吞 & 咽 & 烧 & 喝 & 开 \\
\hline 打 & 晃 & 穿 & 存 & 取 & 驱 & 乐 & 飞 & 逗 & 抖 \\
\hline 停 & 听 & 唱 & 说 & 谈 & 送 & 请 & 灭 & 死 & 想 \\
\hline 烤 & 煎 & 炸 & 量 & 放 & 写 & 拧 & 转 & 挠 & 剪 \\
\hline
\end{tabular}

\section{Copyrights}

Copyright for this article is retained by the author(s), with first publication rights granted to the journal.

This is an open-access article distributed under the terms and conditions of the Creative Commons Attribution license (http://creativecommons.org/licenses/by/4.0/). 